\title{
FAKTOR-FAKTOR YANG MEMPENGARUHI PEMBUANGAN SAMPAH PASAR TRADISIONAL DARFUAR KABUPATEN BIAK NUMFOR TAHUN 2020
}

\section{FACTORS AFFECTING WASTE DISPOSAL OF DARFUAR TRADITIONAL MARKET, BIAK NUMFOR REGENCY IN 2020}

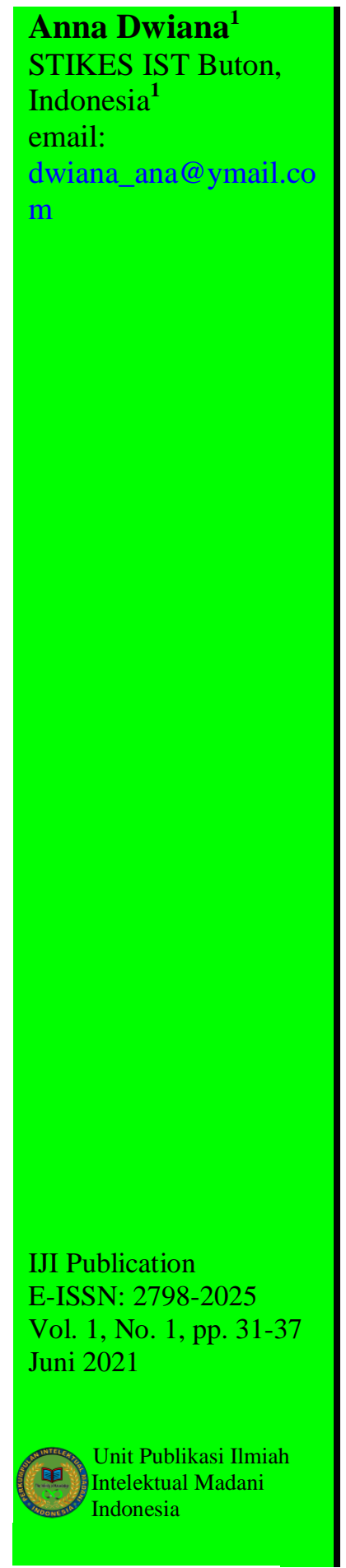

PENDAHULUAN

Sampah erat kaitannya dengan kesehatan masyarakat, karena dari sampah tersebut akan hidup berbagai mikroorganisme penyebab
Abstrak: Permasalahan sampah sudah menjadi persoalan serius terutama di kotakota besar, tidak hanya di Indonesia saja, tapi diseluruh dunia. Produksi sampah yang terus menerus meningkat seiring dengan pertambahan jumlah penduduk, perubahan pola konsumsi, gaya hidup masyarakat telah meningkatkan jumlah timbunan sampah, jenis dan keberagaman karakteristik sampah. Penelitian ini bertujuan untuk mengetahui faktor yang mempengaruhi pembuangan sampah pasar tradisional Darfuar Kabupaten Biak Numfor. Jenis penelitian ini adalah bersifat analitik kuantitatif yang mencoba menggali dan mengapa fenomena kesehatan itu terjadi, dengan desain cross sectional. Adapun populasi dalam penelitian ini adalah 234 responden. Sampel dalam penelitian ini adalah 147 responden, dimana pengambilan sampel adalah secara Random sampling. Hasil uji statistik chi-square diperoleh nilai $\mathrm{X}_{\text {hitung }}^{2}=4,506\left(\mathrm{X}^{2}\right.$ tabel $\left.=3,841\right)$, nilai $\rho=0.039$. Dengan demikian $\mathrm{X}^{2}$ hitung lebih besar dari $\mathrm{X}^{2}$ tabel atau $\rho=0,039$ lebih kecil dari $\alpha=0$, nilai $\mathrm{X}_{\text {hitung }}^{2}=6,835\left(\mathrm{X}^{2}\right.$ tabel $\left.=3,841\right)$, nilai $\rho=0.015$. Dengan demikian $\mathrm{X}^{2}$ hitung lebih besar dari $\mathrm{X}^{2}$ tabel atau $\rho=0,015$ lebih kecil dari $\alpha=0,05$, nilai $\mathrm{X}_{\text {hitung }}^{2}=$ $9,093\left(\mathrm{X}^{2}\right.$ tabel $\left.=3,841\right)$, nilai $\rho=0.004$. Dengan demikian $\mathrm{X}^{2}$ hitung lebih besar dari $\mathrm{X}^{2}$ tabel atau $\rho=0,004$ lebih kecil dari $\alpha=0,05$ maka Ho ditolak dan Ha diterima artinya ada pengaruh antara fasilitas sampah terhadap Pembuangan Sampah Pasar Darfuar Di Kabupaten Biak Numfor tahun 2020.

Kata Kunci : Pengetahuan, Sikap, Fasilitas Pembuangan Sampah.

Abstract: The waste problem has become a serious problem, especially in big cities, not only in Indonesia, but throughout the world. Waste production that continues to increase along with population growth, changes in consumption patterns, people's lifestyles has increased the amount of waste piles, types and diversity of waste characteristics. This study aims to determine the factors that influence the disposal of waste from the Darfuar traditional market in Biak Numfor Regency. This type of research is a quantitative analytic which tries to explore and why health phenomena occur, with a cross sectional design. The population in this study were 234 respondents. The sample in this study were 147 respondents, where the sampling was random sampling. The results of the chi-square statistical test obtained the value of $X 2$ count $=4.506(X 2$ table $=3.841)$, the value of $\rho=0.039$. Thus the calculated X2 is greater than the X2 table or $\rho=0.039$ is smaller than $\alpha=$ 0 , the $X 2$ count $=6.835(X 2$ table $=3.841)$, the value $\rho=0.015$. Thus $X 2$ count is greater than $X 2$ table or $\rho=0.015$ is smaller than $\alpha=0.05$, the value of $X 2$ count $=$ $9.093(X 2$ table $=3.841)$, the value of $\rho=0.004$. Thus X2 count is greater than X2 table or $\rho=0.004$ smaller than $\alpha=0.05$, so Ho is rejected and Ha is accepted, meaning that there is an influence between waste facilities on Darfuar Market Waste Disposal in Biak Numfor Regency in 2020.

Keywords: Knowledge, Attitude, Garbage Disposal Facility.

penyakit (bakteri patogen), dan juga binatang serangga sebagai pemindah/penyebar penyakit (vektor) (Notoatmodjo, 2011). Permasalahan sampah sudah menjadi persoalan serius 
terutama di kota-kota besar, tidak hanya di Indonesia saja, tapi diseluruh dunia. Produksi sampah yang terus menerus meningkat seiring dengan pertambahan jumlah penduduk, perubahan pola konsumsi, gaya hidup masyarakat telah meningkatkan jumlah timbunan sampah, jenis dan keberagaman karakteristik sampah, (Adnani, 2011).

Sampah banyak ditemukan pada tempattempat umum yang menjadi problem kesehatan masyarakat yang cukup mendesak. Karena tempat umum merupakan tempat bertemunya segala macam masyarakat dengan segala penyakit yang dipunyai oleh masyarakat tersebut. Dengan demikian, maka tempat-tempat umum harus memenuhi syarat-syarat kesehatan dalam arti melindungi, memelihara, dan mempertinggi derajat kesehatan masyarakat (Mukono, 2011). Salah satu tempat umum yang menghasilkan sampah adalah pasar.

Negara Indonesia dengan penghasil sampah terbanyak adalah Provinsi Jawa Barat, diikuti oleh Jawa Timur, Jawa Tengah, Sumatera Utara, DKI Jakarta. Sehingga dikatakan pulau Jawa adalah sebagai pulau penghasil sampah terbesar di Indonesia. Sampah yang dihasilkan didominasi oleh sampah rumah tangga dan sampah pasar. Cakupan penanganan sampah oleh pemerintah dirasakan sangat rendah. Sampah yang berhasil dikumpulkan oleh petugas kebersihan di Indonesia hanya sekitar 16,7 juta ton per tahun. Disisi lain, sampah yang tidak terkumpul oleh petugas dinas terkait terhitung sekitar 116 juta ton pertahun, perbedaanya sangat signifikan (Asnita, 2012).

Peranan pasar tradisional di Indonesia sangat penting dalam pemenuhan, terutama bagi golongan masyarakat menengah ke bawah. Pada saat yang sama, pasar dapat menjadi jalur utama untuk penyebaran penyakit seperti kolera dan flu burung. Pada tahun 2015 menunjukkan $60 \%$ masyarakat Indonesia memperoleh bahan pangan dan kebutuhan sehari-hari lainnya dari pasar tradisional. Di Indonesia terdapat sekitar 13.450 pasar tradisional dengan 12.625. 0000 pedagang beraktivitas didalamnya, dan menunjukan terdapat sebanyak $95 \%$ bangunan pasar tradisional sudah tidak layak, kondisi pasar juga sering tidak sehat dengan sistem pembuangan yang tidak baik, drainase yang tidak baik, kebersihan yang buruk sehingga membuat pasar menjadi sumber penyakit (Kemenkes RI, 2015).

Tuntutan masyarakat akan pasar sehat dan pelayanan yang lebih baik semakin tinggi. Oleh sebab itu, pengelolaa pasar "pasar sehat" perlu terus menerus diupayakan. Berdasarkan data Departemen perdagangan tahun 2015, di Indonesia terdapat sekitar 15.560 pasar tradisional dengan sekitar 13,5 juta pedagang yang beraktivitas di dalamnya. Jika pedagang memiliki empat anggota keluarga , maka lebih dari $50 \%$ atau hampir $25 \%$ dari populasi total penduduk Indonesia beraktivitas di pasar. Jika pasar dikelolah dengan sehat, maka masyarakat yang beraktivitas disitu menjadi sehat (Departemen Perdagangan RI, 2016). 
Berdasarkan penelitian yang dilakukan

oleh Dwi Handayani (2018) di pasar Tradisional

Desa Banjarsari Kabupaten Madiun, didapatkan bahwa pengetahuan, sikap dan fasilitas pembuangan sampah mempengaruhi pengelolaan sampah pasar. Hal ini dapat terjadi karena pedagang di pasar tradisional Desa Banjarsari pada umumnya tidak memperhatikan sampah disekitar tempat berjualan, membuang sampah disekitar tempat berjualan. Sehingga pemenuhan fasilitas pembuangan sampah sangat diperlukan.

Penelitian oleh Zafira (2016) di pasar tradisonal Kota Medan menunjukan bahwa kondisi sanitasi di beberapa pasar tersebut masih buruk, seperti sampah yang berserahkan, bahkan bertumpuk tinggi dan diabaikan begitu saja, jalan antar gang uang becek, SPAL yang tidak saniter, serta tempat pengumpulan sampah sementara yang tidak memenuhi syarat kesehatan. Hal ini menunjukkan bahwa sanitasi dasar di pasar belum menjadi perhatian dari pihak yang berkaitan termaksud didalamnya pengelolah dan pemerintah daerah, dan dengan kondisi tersebut mengakibatkan kondisi pasar menjadi tidak sehat, dan tidak nyaman bagi pengunjung yang datang ke pasar tersebut.

Berdasarkan survei pendahuluan yang dilakukan, dari 80 kios yang disurvei, masih banyak sekali sampah yang berserakan di depan stand atau di depan kios-kios pedagang. Selain itu, di pasar tersebut juga tidak tersedia tempat pembuangan sementara atau TPS, hal ini dapat mengganggu para pengunjung pasar. Para pedagang sebagian membuang sampah mereka di sungai belakang pasar dan sebagian pedagang lain membawa sampah mereka dan membuangnya ke TPS yang berada di pasar lain yang bertempat di kecamatan yang berbeda. Hal ini dikarenakan minimnya fasilitas persampahan di pasar tersebut.

Beberapa faktor tersebut sangat penting dalam menentukan perilaku membuang sampah oleh pedagang di pasar tersebut. Dari permasalahan yang di temukan di pasar tradisional di atas, terlihat bahwa para pedagang perlu memperhatikan pengelolaan sampah karena pengelolaan sampah harus dilakukan dengan benar dan efektif dan memenuhi persyaratan sanitasi (Enjang, 2010). Maka dari itu, perlu adanya perilaku pedagang pasar yang baik dalam bentuk pengetahuan dan sikap dalam pengelolan sampah, pemenuhan fasilitas pembuangan sampah dan tindakan petugas pasar dalam pengelolaan sampah di pasar, hal ini untuk meminimalisir sampah berserakan di sekitar kios dan stands para pedagang sehingga dapat tercipta kebersihan lingkungan pasar. Oleh karena itu, tujuan penelitian ini adalah untuk mengetahui faktor-faktor yang mempengaruhi pembuangan sampah pasar tradisional Darfuar Kabupaten Biak Tahun 2020.

\section{METODE}

Jenis penelitian yang digunakan pada penelitian ini adalah penelitian kuantitatif yang menggunakan desain cross sectional. Rancangan cross sectional merupakan rancangan penelitian yang pengukuran dan 
pengamatannya dilakukan secara stimulan pada

suatu saat atau sekali waktu (Notoatmodjo, 2010).

\section{HASIL DAN DISKUSI}

Jumlah penduduk Kabupaten Biak Numfor tahun 2019 adalah 145.425 jiwa yang terdiri dari 74.343 jiwa penduduk laki-laki dan 71.082 jiwa penduduk perempuan. Jumlah ini menunjukkan penduduk laki-laki lebih banyak dari penduduk perempuan. Rasio jenis kelamin Kabupaten Biak Nomfor pada tahun 2019 menunjukan angka diatas $100(104,59)$ yang berarti setiap 100 perempuan terdapat sekitar 105 laki-laki. Kepadatan tertinggi terjadi di Distrik Biak Kota, yakni hamper mencapai 1.030- 1.031 jiwa per $\mathrm{km}^{2}$ dan Distrik Samofa (156-157 jiwa perkm² ${ }^{2}$. Sedangkan kepadatan terendah terjadi di Distrik Bondifuar, yakni mendekati 3-4 jiwa per $\mathrm{Km}^{2}$.

\section{Analisis Univariat}

1. Pembuangan Sampah Pasar

Tabel 1

Distribusi Frekuensi Berdasarkan Pembuangan Sampah Pasar Yang Terdapat Di Pasar Darfuar Kabuppaten Biak Numfor Tahun 2020

\begin{tabular}{clcc}
\hline No & Pembuangan Sampah Pasar & $\begin{array}{c}\text { Jumlah } \\
(\mathrm{n})\end{array}$ & $\begin{array}{c}\text { Persen } \\
(\%)\end{array}$ \\
\hline 1 & Memenuhi Syarat & 60 & 40,8 \\
2 & Tidak Memenuhi Syarat & 87 & 59,2 \\
\hline & Total & 147 & 100
\end{tabular}

Sumber: Data Primer, 2020.

Berdasarkan tabel 1 dapat diketahui bahwa sebagian besar Pembuangan sampah pasar oleh responden adalah yang tidak memenuhi syarat yaitu 87 orang dengan persentase 59,2 \%. Dan sebagian kecil adalah yang memenuhi syarat dengan jumlah 60 orang dengan persentase $40,8 \%$.
2. Pengetahuan

Tabel 2

Distribusi Frekuensi Berdasarkan Pengetahuan Responden Yang Terdapat Di Pasar Darfuar Kabupaten Biak Numfor Tahun 2020

\begin{tabular}{cccc}
\hline No & Pengetahuan & $\begin{array}{c}\text { Jumlah } \\
(\mathrm{n})\end{array}$ & $\begin{array}{c}\text { Persen } \\
(\%)\end{array}$ \\
\hline 1 & Baik & 56 & 38,1 \\
2 & Kurang & 91 & 61,9 \\
\hline & Total & 147 & 100 \\
\hline
\end{tabular}

Sumber: Data Primer, 2020.

Berdasarkan Tabel 2 dapat diketahui bahwa sebagian besar responden yang berpengetahuan kurang tentang pembuangan sampah pasar yang benar dengan jumlah 91 orang dengan persentase $61,9 \%$. Dan sebagian kecil adalah yang berpengetahuan baik dengan jumlah 56 orang dengan persentase $38,1 \%$.

3. Sikap

Tabel 3

Distribusi Frekuensi Berdasarkan Sikap Responden Yang Terdapat Di Pasar Darfuar Kabupaten Biak Numfor Tahun 2020

\begin{tabular}{cccc}
\hline No & Pengetahuan & $\begin{array}{c}\text { Jumlah } \\
(\mathrm{n})\end{array}$ & $\begin{array}{c}\text { Persen } \\
(\%)\end{array}$ \\
\hline 1 & Baik & 62 & 42,2 \\
2 & Kurang & 85 & 57,8 \\
\hline & Total & 147 & 100 \\
\hline
\end{tabular}

Sumber: Data Primer, 2020.

Berdasarkan tabel 3 dapat diketahui bahwa sebagian besar responden yang bersikap kurang tentang pembuangan sampah pasar yang benar dengan jumlah 85 orang dengan persentase 57,8 \%. Dan sebagian kecil adalah yang bersikap baik dengan jumlah 62 orang dengan persentase $42,2 \%$.

4. Fasilitasi Sampah

Tabel 4

Distribusi Frekuensi Berdasarkan Sikap RespondenYang Terdapat Di Pasar Darfuar Kabupaten Biak Numfor Tahun 2020

\begin{tabular}{cccc}
\hline No & Fasilitas Sampah & $\begin{array}{c}\text { Jumlah } \\
(\mathrm{n})\end{array}$ & $\begin{array}{c}\text { Persen } \\
(\%)\end{array}$ \\
\hline 1 & Ada & 76 & 51,7 \\
2 & Tidak Ada & 71 & 48,3 \\
\hline & Total & 147 & 100 \\
\hline
\end{tabular}

Sumber: Data Primer, 2020. 
Berdasarkan tabel 4 dapat diketahui

bahwa sebagian besar ada fasilitas sampah pasar yaitu dengan jumlah 76 tempat sampah dengan persentase 51,7 \%. Dan sebagian kecil adalah responden yang tidak ada fasilitas sampah dengan jumlah 71 tempat sampah dengan persentase $48,3 \%$.

\section{Analisis Bivariat}

1. Pengaruh Pengetahuan Responden Terhadap Pembuangan Pasar Darfuar

Hasil uji statistik chi-square tentang pengaruh antara pengetahuan terhadap Pembuangan Sampah Pasar Darfuar diperoleh nilai $X_{\text {hitung }}^{2}=4,506\left(X^{2}\right.$ tabel $\left.=3,841\right)$, nilai $\rho$ $=0.039$. Dengan demikian $X^{2}$ hitung lebih besar dari $\mathrm{X}^{2}$ tabel atau $\rho=0,039$ lebih kecil dari $\alpha=$ 0,05 maka Ho ditolak dan Ha diterima artinya ada pengaruh antara pengetahuan terhadap Pembuangan Sampah Pasar Darfuar Di Kabupaten Biak Numfor tahun 2020.

2. Pengaruh Sikap Responden Terhadap Pembuangan Pasar Darfuar

Hasil uji statistik chi-square tentang pengaruh antara sikap terhadap Pembuangan Sampah Pasar Darfuar diperoleh nilai $\mathrm{X}^{2}$ hitung $=$ $6,835\left(\mathrm{X}^{2}\right.$ tabel $\left.=3,841\right)$, nilai $\rho=0.015$. Dengan demikian $\mathrm{X}^{2}$ hitung lebih besar dari $\mathrm{X}^{2}$ tabel atau $\rho=0,015$ lebih kecil dari $\alpha=0,05$ maka Ho ditolak dan Ha diterima artinya ada pengaruh antara sikap terhadap Pembuangan Sampah Pasar Darfuar Di Kabupaten Biak Numfor tahun 2020.
3. Pengaruh Fasilitas Sampah Terhadap

Pembuangan Pasar Darfuar

Hasil uji statistik chi-square tentang pengaruh antara fasilitas sampah terhadap Pembuangan Sampah Pasar Darfuar diperoleh nilai $X_{\text {hitung }}^{2}=9,093\left(X^{2}\right.$ tabel $\left.=3,841\right)$, nilai $\rho$ $=0.004$. Dengan demikian $X^{2}$ hitung lebih besar dari $\mathrm{X}^{2}$ tabel atau $\rho=0,004$ lebih kecil dari $\alpha=$ 0,05 maka Ho ditolak dan Ha diterima artinya ada pengaruh antara fasilitas sampah terhadap Pembuangan Sampah Pasar Darfuar Di Kabupaten Biak Numfor tahun 2020.

\section{Pengaruh Pengetahuan Responden Terhadap Pembuangan Sampah Pasar}

Berdasarkan hasil penelitian ini diperoleh bahwa responden yang berpengetahuan baik lebih banyak memenuhi syarat dalam membuang sampah dibandingkan yang tidak memenuhi syarat dalam membuang sampah. Hal ini dapat terjadi karena responden yang berpengetahuan baik ternyata ada juga yang melakukan pembuangan sampah pasar sesuai dengan syarat kesehatan, meskipun ada juga yang memiliki pengetahuan baik, namun masih membuang sampah tidak memenuhi syarat kesehatan. Responden yang mempunyai pengetahuan baik dan memenuhi syarat dalam membuang sampah, dapat terjadi karena biasanya kesadaran yang didapatkan oleh para pedagang setelah diadakannya penyuluhan oleh dinas kebersihan ataupun informasi-informasi yang disampaikan oleh petugas dinas kebersihan Kabupaten Biak Numfor. Namun demikin masih ada juga para responden (pedagang) yang 
tidak memiliki kesadaran tentang bagaimana membuang sampah pasar pada tempatnya yang sesuai dengan persyaratan kesehatan. Hal ini perlu diperhatikan oleh petugas kebersihan Kabupaten Biak Numfor agar pembuangan dan pengelolaan sampah pasar Darfuar dapat dilaksanakan sesuai dengan syarat kesehatan.

\section{Pengaruh Sikap Responden Terhadap Pembuangan Sampah Pasar}

Berdasarkan hasil penelitian ini diperoleh bahwa responden yang bersikap baik lebih banyak memenuhi syarat dalam membuang sampah dibandingkan yang tidak memenuhi syarat dalam membuang sampah. Hal ini dapat terjadi karena responden yang telah memiliki pengetahuan baik tentang membuang sampah pasar, biasanya diikuti dengan sikap yang positif/baik pada saat membuang sampah pasar. Sikap positif/baik tersebut dapat digambarkan misalnya mereka dapat membuang sampah pada tempatnya dan di setiap kios disediakan tempat sampah sendiri. Namun masih ada juga responden yang memiliki sikap yang kurang dalam membuang sampah pasar yang digambarkan misalnya tidak menyiapkan tempat sampah sendiri di setiap kiosnya, sampah dibiarkan berhamburan di sekitar kios. Hal ini menunjukkan kurang sadarnya akan kebersihan pasar, kurang paham tentang pentingnya kebersihan pasar.

\section{Pengaruh Fasilitas Sampah Terhadap Pembuangan Sampah Pasar}

Berdasarkan hasil penelitian ini dapat diperoleh bahwa responden yang ada fasilitas sampahnya lebih banyak memenuhi syarat dalam membuang sampah dibandingkan yang tidak memenuhi syarat. Hal ini dapat terjadi karena biasanya yang memiliki fasilitas sampah berarti seseorang yang memiliki sikap dan pengetahuan yang baik berdasarkan penelitian ini. Responden banyak mengatakan mereka merasa termotivasi untuk menyediakan fasilitasfasilitas tempat sampah setelah diberikan informasi dan penyuluhan oleh dinas kebersihan Kabupaten Biak, mereka termotivasi untuk menyediakan fasilitas tempat sampah baik untuk tempat sampah basah maupun kering. Namun demikian masih ada juga yang tidak mau menyediakan tempat-tempat sampah, mereka merasa tidak penting untuk menyediakan tempat-tempat sampah, nanti kemudian petugas kebersihan atau petugas sampah yang akan membersihkan sampah yang berserahkan. Yang banyak berhamburan di sekitar sampah adalah sampah sisa-sisa makanan dan sisa-sisa sayuran. Masih banyak pedagang yang belum mempunyai kesadaran akan pentingnya menjaga kebersihan pasar. Oleh sebab itu pentingnya penyuluhan-penyuluhan yang lebih sering dilakukan terhadap masyarakat agar lingkungan lebih menjadi sehat.

\section{KESIMPULAN}

Berdasarkan hasil penelitian tersebut diatas, maka hal-hal yang dapat disimpulkan bahwa: (1) Ada pengaruh antara pengetahuan terhadap Pembuangan Sampah Pasar Darfuar Di Kabupaten Biak Numfor tahun 2020; (2) Ada pengaruh antara sikap terhadap pembuangan 
sampah pasar Darfuar di Kabupaten Biak

Numfor tahun 2020; (3) Ada pengaruh fasilitas tempat sampah terhadap pembuangan sampah pasar Darfuar di Kabupaten Biak Numfor tahun 2020. Oleh karena itu, pedagang pasar dapat menyediakan tempat-tempat sampah baik tempat sampah kering maupun tempat sampah basah dan sebelum meninggalkan pasar, para pedagang membersihkan kiosnya terlebih dahulu agar sampah tidak berserahkan di manamana, serta petugas kebersihan sebaiknya banyak memberikan informasi dan penyuluhanpenyuluhan kepada masyarakat agar dapat membuang sampah pasar pada tempatnya dan menjaga kebersihan pasar.

\section{REFERENSI}

Amalia, Imanda. (2015). Hubungan Antara Pendidikan, Pendapatan, dan Perilaku Hidup Bersih dan Sehat (PHBS) pada Pedagang Hidangan Istimewa Pasar Kliwon dan Jebres Kota Surakarta. Program Studi Kesehatan Masyarakat Fakultas Ilmu Kesehatan Universitas Muhammadiyah Surakarta.

Azwar, A. (2010). Pengantar Ilmu Kesehatan Lingkungan. Jakarta : Rineka Cipta.

Bahri, Samsul. (2016). Faktor-Faktor yang Mempengaruhi Sanitasi Pasar Bina Usaha di Gampong Ujong Kalak Kecamatan Johan Pahlawan Kabupaten Aceh Barat. Program Studi Ilmu Kesehatan Masyarakat, Universitas Teuku Umar, Meulaboh-Aceh Barat. Skripsi.

Beni, Martinus Tulit. (2015). Pengaruh FaktorFaktor Sosial-Ekonomi Terhadap Perilaku Pengelolaan Sampah Domestik di Nusa Tenggara Timur. Program Studi Ilmu Lingkungan, Universitas Nusa Cendana, Semarang. Vol. 12.
Candra, Fitriana Ayu. (2015). Pengelolaan Sampah Pasar Tradisional dan Tindakan Pedagang Pasar dengan Kebersihan Lingkungan Pasar. Program Studi Kesehatan Masyarakat Universitas Jember.

Dwi Handayani. (2018). Faktor-Faktor Yang Mempengaruhi Pengelolaan Sampah Pasar Tradisional Desa Banjarsari Wetan Kabupaten Madium. Skripsi. Peminatan Kesehatan Lingkungan.

Damayanti, Ria. (2016). Faktor-Faktor yang Berhubungan dengan Perilaku Pedagang dalam Membuang Sampah di Pasar Sentral Sekura. Program Studi Kesehatan Masyarakat Sekolah Tinggi Ilmu Kesehatan Kapuas Raya Sintang.

Damsar. (2010). Sosiologi Pasar. Jakarta: Raja Grafindo Persada.

Depkes RI. (2016). Tugas Petugas Kebersihan Tiap Kota. Jakarta : Dutjen PMM dan PL.

Dinas Kebersihan dan Pertamanan. 2016. Pekerjaan Penyusunan Masterplan TPA Kaliabu. Sidoarjo: CV. Centrum Konsulindo.

Entjang, I. (2010). Ilmu Kesehatan Masyarakat. Bandung: PT. Citra Aditya Bakti.

Kepmenkes RI. (2008). Pedoman Penyelenggaraan Pasar Sehat. Jakarta. 